\title{
A QUALITATIVE INVESTIGATION ON THE SUCCESSFUL TURNAROUND STRATEGY FROM TOP LEADER PERSPECTIVES: EXAMPLES FROM INDONESIA
}

\author{
Yulihasri $^{1}$, Arief Prima JOHAN ${ }^{2}$, Rebi Fara HANDIKA ${ }^{3}$, Herri $^{4}$ \\ Andalas University, Padang, Indonesia \\ E-mails: ${ }^{1} y$ ulihasri_eri@yahoo.com; ${ }^{2}$ ariefprimajohan@gmail.com (corresponding author); \\ ${ }^{3}$ rfhandika@gmail.com; ${ }^{4}$ herri.unand@gmail.com
}

Received 06 January 2018; accepted 22 May 2018

\begin{abstract}
Turnaround process involved many approaches of strategic and tactical attempts. However, such knowledge are difficult to identified since many previous studies only focused on what constitute successful turnaround, and limited to the use of financial data. As turnaround is a transformational process comprehend every element of organization, ploy on implementing and orchestrating such strategic action should be determined by company's top leaders. The purpose of this study was to explore the way in which leaders manage the company's turnaround process and their leadership style through a qualitative study in Indonesian business. Drawing from several top managers in various industry in Indonesia, the result showed that there are many attempt should consider on implementing turnaround process. Financial restructuration, employee's transformation initiative, and business reengineering process are imperative approaches. Furthermore, leaders need to consider top-down approach on decision making, attention to detail, and open communication to gain employees commitment.
\end{abstract}

Keywords: turnaround strategy, transformational process, strategic leadership, top leaders, qualitative method.

JEL Classification: M12, M14.

\section{Introduction}

Determinants of company's performance are still untapped. Scholars have tries to answer such questions from various perspectives such as industrial organization (Porter 1979), resources based (Prahalad and Hamel 1990, Barney 2001), and strategic leadership (Hambrick and Mason 1984, Hambrick 2007). However, the results were inconsistent and present contradicting results. It indicated dynamic development of concept and theory of strategic management.

At least, there are two main reasons causing inconsistencies. First, the contingency theory explains that there are contextual factors which differentiate one organization to another. This theory assumes that every organization is unique, therefore each organization should be managed distinctly. Second, organization exists in an environment which change regularly, by design or accident, and organization always carries out adaptation process to such changes
(Morgan 2006). Hence, changes in the environment should change the organization.

Rather seeking inconsistency, inquiry on company's strategy should focus on specific context. Narrow focus on a particular context and situation were believed more practical. Scholars have done such approach like studying strategy in particular market, specific countries, discussing situational event, changes, value chain, business reengineering process, and turnaround strategy. Turnaround strategy is an interesting contextual event yet it has not received sufficient attentions from scholars. Limited studies found investigating the implementation of such strategy. Turnaround strategy concerns on the issues at the internal recovery processes such as change management and organizational transformation (Boyd 2011). Such attempt were motivated by the substantial decline of company's performance (Boyd 2011).

Copyright $\odot 2018$ The Authors. Published by VGTU Press.

This is an Open Access article distributed under the terms of the Creative Commons Attribution License (http://creativecommons.org/licenses/by/4.0/), which permits unrestricted use, distribution, and reproduction in any medium, provided the original author and source are credited.. 
The roles of leader during decreasing were imperative (Abebe 2010). Leaders have significant power in determining company's survival. Top leaders have legitimate authority to design and execute an effective turnaround strategies needed to recover company's performance (Lohrke et al. 2004). As disturbance handler, leaders are forced to response through strategic and tactical corrective acts (Finkeilstein et al. 2009). Several previous studies in turnaround has focused on understanding the effect of executive-level characteristics on turnaround performance such as board composition (Zimmerman 1989, Mueller and Barker 1997), turnover and replacement (Arogyaswamy et al. 1995, Barker et al. 2001, Boyne and Meier 2009) as well as executive causal attribution (Barker and Patterson 1996, Barker and Barr 2002). Since significant role of leaders is not only in deciding strategy, but also approaches on implementing such decision, it is necessary to inquire detail action of leaders on leading turnaround process.

Despite of extensive studies and attempts to understand the determinants of successful turnaround, such results are depending on the organizational contingencies especially the process that required transformation of employees' mind-set (Day and Moorman 2013). Substantial amount of insight embedded in such process that cannot be understood by merely rely on statistical and survey approaches. Uncovering of turnaround approaches should engage with quantitative method which allows to gather deeper knowledge and experiences. However, there limited studies on describing how the implementation of turnaround using such method. Furthermore, there are many Indonesia's companies that successfully recover after 1998 and 2008 crisis (Herri et al. 2017).

This paper attempts to identify successful turnaround implementation process from the perspective of strategic leadership. Since lack of evidences regarding how the turnaround process are implemented by leader, we will investigate the approaches directly from top leaders who successfully recover their companies. Details of tactical implementation will also inquire to comprehend the understanding of turnaround process in several Indonesian Companies.

\section{Turnaround strategy}

Turnaround strategy is defined as company attempt in a particular set of time or period to sustain or change the company's unique superiority and to restore its function as profit making tool (Harker and Sharma 2000). This strategy is initiated and motivated by the turnaround situation which indicated by downfall of company's performance. In turnaround situation, companies were faced at a particular situation which was called as severity that threatened core competence and company's survival capability (Day and Moorman 2013).
Turnaround occurs when firm undergoes substantial decreasing performance decline over a certain period. Successful process was determined by its ability to reverse the declined turnback in to a normal performance and achieve sustained profitability (Barker and Duhaime 1997). Day and Moorman (2013) defined turnaround strategy as changes which are rapidly carried out as the company needs to respond the issues on performance decline such as the decline in market share, profitability, efficiency, and among others. Brege and Brandes (1993) also defined turnaround strategy as a process to improve the company's bad performance into a better and more sustainable growth (Harker and Sharma 2000, Cameron et al. 1987). An organization was considered in turnaround situation if its performances was declining in two consecutive years below free risk interest rate (Francis and Desai 2005). According to Lohrke et al. (2004) turnaround process consists of three steps. First, identifying causes of ongoing decline which were usually related to either environmental changes or internal weakness. Some cases involved both dimension. Next, formulates and implements appropriate strategy to overcome the causes of decline. Finally, evaluation of turnaround process and conducted necessary adjustment (Pearce and Robbins 1993, Morrow et al. 2004, 2007, Van Wittelstuijn 1998).

\section{Leaders and turnaround}

Upper echelons theory argued that top leaders are the most responsible actor in company's survival (Hambrick and Mason, 1984). The chosen strategy such as turnaround approaches is also determined by leader. Day and Moorman (2013) states that the implementation of turnaround strategy needs great intervention on transformation plan as well as support from top management. In implementing turnaround strategy, top leader needs to design many transformational changes such as system, culture, and employee attitude (Evans et al. 2013). Those changes should be properly grasped by every elements in the organization, thus it builds trust toward leader and result of turnaround (Boyd 2011, Lawson and Price 2003). Lawson and Price (2003) further explained that transformation process need to be precisely defined and effectively communicated to every elements of the company.

The success of turnaround not only needs several attempts to make internal changes but also process to communicate transformation with public and consumers (Day and Moorman 2013). Consumers and public need to know that the company has initiated changes, thus it helps to rebuild consumers' trust toward the company (Evans et al. 2013, Harker 2001). Although, there is only small possibility that consumers can be rapidly influenced by the initiated changes. At least, the company has created awareness to the public about their strategic action (Smith and Graves 2005, Lawton et al. 2011). 
The changes also need to be done in every companies' function especially at the financial structure. Turnaround process was mostly done through a set of efficiency attempts and capital reconstructions (Smith and Graves 2005, Schoenberg et al. 2013, Pretorius 2008). Efficiency is needed as an attempt to restore the business process (Lawton et al. 2011). Furthermore, putting more investment into the company is also an important step to reinitiate new strategic attempts (Lawton et al. 2011, Smith and Graves 2005, Panicker and Manimala 2015).

\section{Method}

Qualitative research approach were selected as research design. Using such approach many human perception and understanding regarding the topic could be generated (Stake 2010). Qualitative approach usually conducted through investigating small sample of individuals, groups, or events (Sekaran 2003). This approach enabled to gain and describe deeper understanding of informant experiences (Creswell 2009, Merriam 2009). Furthermore, qualitative method could mitigate the gap of existing literature of turnaround strategy because of its ability to generated tacit knowledge and experiences.

Qualitative data was obtained through in-depth interviews with several top leaders in Indonesia's company who had successfully recover their companies from turnaround situation. Informants comprised of six business practitioners who hold top management position in their company. We conducted face to face interview with informants separately by asking them open question related to their business setting and managerial experiences on turnaround process. After interviewing all informants, data analysis was started by making transcript for each results. In order to generate the results, contents of transcript were analysis using panel judgment among authors simultaneously.

\section{Result and discussion}

Interviews were conducted with six executive directors of diverse companies. Those persons were known as successful leaders on recovering their company from turnaround situation. Most of them are modest to high tenure executives with minimum five years of services as top manager, three are company's founder. The leaders are coming from various sector. One informant was served as top leader in private hospital, one leader was produced ceramics, one person from each textile and culinary industry, one person was from farm industry, and another was from heavy equipment sector. The eldest executive was 54 years old while the youngest leader was 33 years old.

All informant had experiencing complete turnaround situation that started from significant decreasing of performance, recovering process, and finally achieve industry normal return. Three informant were entering companies as turnaround occurred and detected, which means they are replacement of previous leaders. Three other were experiencing initial symptoms of turnaround and being in companies while such process occurring. According to such informant, the very beginning symptoms of turnaround were highly difficult to notice. They argued that substantial decrease of company's performance was noticed after formal period of performance measurement or when companies were in poor position of working capital.

There are few causes that substantially trigger turnaround process. First, lack of ability to identify and anticipate actions of competitors. As minor decreasing of sales occurred in company, few leaders directly reactive actions on decreasing their operational cost. However, such actions were not backed with external assessment of competitor's moves. After substantial cutback of return, leaders from Textile Company and Culinary Sector started to look into their competitor's action, and realized that their core products were imitated and modified by their competitor with some additional features. As one of informant said:

"We are over focused to our self, and when some
bad things happens, we look into our self. I figured
it because the entire people in this company are too
comfort with what they doing as a part of good per-
formance's company. While in slight decreasing ofour
sales, my competitors were producing goods that simi-
lar to my products. They produced it in high volume,
and sell those with more competitive price". (Textile
Company)

Poor corporate culture was also a major cause of turnaround situation. Bad circular of communication was occupied within companies. Major corporate communication in Farm Company's style were not in line with local custom where most employee are local society. Most communication style are characterized with one-way communication and inappropriate use of words and styles. Leaders in such company's often used bad inappropriate language when directing their followers. Poor communication were also caused by improper compensation design. Employees were compensated on fix fare despite of their performance, in turn affecting their work in daily operation. The leader argued:

"We are state owned enterprise, and enjoyed capital and working capital subsidies from parent company. There was communication culture within this company that could be identified as autocratic while local culture is egalitarian. Many young leader did not show their respect to their follower even to the elder followers. This style was conflicting with such local culture. This style decreased moral of employees". (Farm Company) 
"Since each employees were paid on the fix fare, they were not accustomed to performance based compensation. Many of them were laze because despite of being diligent or not, their pay was fix. It affected their drive to work. I could not found any initiative action from employees to improve their productivity. This was a very bad culture". (Farm Company)

Different kind of poor corporate culture was also occurred in company from ceramics industry. Lack of innovation had lead this company to operational inefficiency. Inability to seek efficient production material and design their logistic transportation had substantially increase their overhead. Despite of their modern and leading equipment among similar companies, they could not capitalize such assets because hold too strong to the way the work. Similarly, company from culinary sector was lack of contingency plan that make them struggle to recover when one dimension of their business are in the trouble. Another caused that mentioned to be a trigger of turnaround situation was pressure from slowing down of economy condition. Companies confessed that decreasing of disposable income of society had affected their return. Inability to predict when this trend will rebound and also failure to take mitigate action to survive have make the economy condition impact became worse.

Based on data, companies could slumped into turnaround situation because of three condition. First, lack of vision that reflected from inability to predict and anticipate competitive movement, poor corporate culture that overburden companies when they need to adapt, and lack of ability to manage in slow economy condition. More importantly, leader from such companies agreed that their ignorance to the initial loss should be accounted as one of the cause of turnaround situation.

\section{Turnaround strategy}

Most companies are relying on the financial and employees restructuring process, reengineering and redesign of their business process, and shaping new culture within companies in order to implement turnaround strategy. Despite of such strategy, not all companies conducted a robust strategic plan preceding their decision. Except leaders from Ceramics Company, other top executives made decision based on simple observation, previous experiences, and judgment. However, they were design detail operational action plan to translate such strategic decision. As some informant said:

"I asked my staff to observe few hospital in order to seek what dimension that contributed to their revenue. After that I asked them to hand over their work to me that I used as information to make a better decision. It was only a simple research, we do not used specific methodologies. However, I validated the result with my previous experiences". (Private hospital)

"In order to make strategic decision to recover my company, I tend to use my judgment on surrounding. I have been in this industry for many years, and I have passed this situation many time". (Textile Company)

In contrast to other leaders, top executive of Ceramics Company was conducted more robust analysis. The company measured each dimension of its business process, financial structure, as well as their market value carefully before came up with specific strategic decision. Furthermore, company also assess their personnel as well as their culture thoroughly using both internal and external consultant. Consequently, this company have better operational tactics rather than other five companies that frequently change and modified their action plan.

\section{Financial strategy}

Companies in turnaround situation were identified with low level of working capital and high debt. In order to recover, companies need to generate sufficient level of additional financing. However, it was not easy for companies to get financing from bank since they were in high risk situation. Consequently, companies in such condition should able to find alternative source of fund to finance their turnaround process. Liquidation of few assets was an option for company to gain sufficient working capital. Leader of Heavy Equipment Company and Culinary Company had sold few company's assets to recover their working capital. Companies should realize that they might end up with higher cost of capital in order to find money. Leasing Companies was an alternative institution that used by Ceramics Companies to generate their financing for working capital. However, they had to commit to higher level of interest rate. Leader from such company argued that:

"None of banking institution could helped us at that time. They said that we were too risky and it was against regulation for them if they lend us money. It was a challenge to find another sources of fund. We have call for shareholders to put their additional capital. It could only helped us on restructuring our debt, but we still short for working capital... fortunately we could make a deal with leasing company to finance some aspects of our working capital" (Ceramics Company)

"We have to release some of our important assets for sale and mortgage. It was very helpful decision because not only we generated fund, but we were also decreasing overhead cost of such assets that we have sold”. (Heavy Equipment Company) 
Cost-benefit analysis came as crucial strategy in turnaround process. Leaders in turnaround situation were highly motivated to take attention to details. The purpose was to achieve high level of efficiency. All leaders argued that they involved actively in calculating specific detail of cost-benefit of business process. They suddenly became much more careful than they used to. As one leader confess:

"I asked my finance staffs to provide me with all detail of transaction, then we calculate value of each process according to its cost and benefit. There were many inefficient activity that should not be taken, even some of those did not create additional value". (Private Hospital)

"We changed our compensation system from fix fare to variable fare based on the amount of tea leaves that picked by employees. This approach have made us easier to calculate our overhead cost". (Farm Company)

\section{People management}

As company running in poor condition, leaders were struggling with many issues of managing people. Employees tend to resist new way of doing specific work while companies leader try to fix cost structure. In order to create favorable impact, leaders have to think strategically in long term perspectives of companies' interest. All leaders agreed that they were made a long term plan for managing people. Each leaders had made formal planning of their employees along with expected skill and desired competencies leader from Textile Companies provide specific training program for their employees on how to produce new line of product while he understand that company's was not in favorable financial situation. Similarly, leaders from Culinary Company and Ceramics Company hired and hijacked new talent sacrificing considerable cost to ensure that their turnaround process run well.

Laying off many employees could not be avoided in turnaround situation. Companies had to let numbers of their employees go. This action were taken either to improve their cost balance or to create bargaining position. Rather than firing employees, most leaders tend to use early retirement program as first attempt. This approach have helped them to not making the situation any worse. Furthermore, laying off several employees could also use to increase bargaining position of leaders. They believed that such approach could help them to express their commitment toward transformation program, and expected their employees to come along.

Unique way of managing people was found in Farm Companies. They used firing - hiring approach to manage employee resistance toward transformation program. At the beginning, they offer early retirement program with attractive benefit to their employees. Many of them participated with such program. Understand with unproductive culture of their employee, leaders believed that their employees will spend their money taken from retirement program unwisely. Consequently, within a year, retired employees asked for their job back. Company offered them their previous job, but it has transformed in a new design of work and compensation. At this point, company has favorable bargaining position over their employees in order to expect them engage in turnaround process. As the leaders argued:

"First, we firing them (employees) with benefit. We knew that the benefit will not last long, and they will asked their job back. When they came, we offered them with new way of work and compensation system. It work". (Farm Company)

Leaders in turnaround situation should also maintain their companies work atmosphere. As realized that company are in poor performance, employees will have unsafety feeling. At this condition, leaders should ensure that high performance people will still in a team, so they have courage and ambition to prove their performance. Actually, company need experienced people with sufficient knowledge and know-how of business process to involve in transformation process. As a leader confessed:

"Although I bring new face to organization, I still need knowledge and know-how of current employees. However, we are at the top should create competitive atmosphere in order to maintain competitiveness among employees". (Ceramics Company)

\section{Business process and operational}

Operational aspects were consider as the most imperative target to be recover in turnaround process. All leaders agreed and believed that their success in leading such recovery dimension will determine overall performance. Most leaders were relied on the reengineering process and simultaneously transform company's culture. In reengineering of their business process, leaders was seeking for favorable input and technology as well as redesign their distribution chain. As they said:

"Our loan were just approved. Our companies should in the sufficient level of solvability. However, if we used current product and input, we could not make any profit. Our current products have high quality which produced using expensive material. Consequently, we change our input in order to produce standard quality product". (Ceramics Company)

"From the beginning, this hospital was prepared for middle to high income consumers. However, the situation was contradicted with its resources. Previously, 
we did not have any reputable doctor, our layout did not indicated premium services, and our administration process was slow. Along decreasing period we recruited reputable doctors and offered them a very good benefit, we invested substantially to our facilities and layout, as well as in management information technology". (Private Hospital)

In order to recover their operational process, leaders in turnaround companies had to sacrifices some of their important resources. Previous important products, margin, and convenience business process should be targeted to transform. However, leaders feels it was a necessary sacrifices to be taken. The said it will make short fall of company's performance, but the shortcoming will appears after several period. All leaders confessed separately that their performance were more decreased after taking action on turnaround planning. However, it will rebound after stable operational business process implemented. The trend of such phenomena was in U-shape curve. Decreasing performance will touch its peak, then it will rebound to a normal performance. Some leaders argued that:

"After my product was being imitated, I have to stop to produce it for a while. Consequently, I only sell standard product in order to maintain our revenue while simultaneously modified our previous competitive product before it re-launching". (Textile Company)

"We had invested substantially on new technology, we also had borrowed a lot of money for our working capital. As result, we have to cut our cash cycle, and produce goods that could be sell quickly. In order to do such thing, we increase our production to achieve economic of scale, and sell it in a very competitive price. We lose much of our margin". (Ceramics Company)

As turnaround occurred, most leaders realized that they cannot rely on only few line of products or services. They have learned in expensive cost from turnaround situation that diversified is a must. Consequently, they were quickly initiate diverse product in order to maintain their portfolio. They believed such approach will lessen their risk when bad things happen. As some leaders said:

"In preceding condition, we only offered three variant of tea. We could not relied on such products since our competitors were also produce similarly. Currently, we had expand our variant in 13 kind of tea with different level of quality". (Farm Company)

"Our ceramics had stuck in market. Hence, we must offered new product. But we anticipate future trends, so we still produced that stuck product. We believed that economy will grow again. Recently we have made nine lines of our product with each specific market". (Ceramics Company)

\section{Leadership style}

Although contingency theory argued that leadership style should be according to organizational context and condition, it was appear that leaders in turnaround situation came up with similar style. In order to recover their company's condition, executives tend to use top down approaches in order to make important decision and strategic direction. Second, they appeared to be very detail and made extra attention to process. Finally, leaders in turnaround situation are maintain open communication in order to establish employees' commitment.

\section{Top down approach}

Since turnaround is a strategic issue, leaders at the top were the first group who realized how bad the situation. Their judgment on such issues as well as their perception on the consequences that might occurred determined the definition of current company's situation. Leaders' insight on companies' situation have made them understand and comprehend what companies should do on recovering performance. As some leaders argued:

"Strategic direction were design by top management. They were together formulate long term plan of what companies should implemented for a particular period. However, many part of input for such decision were generated from our employees". (Ceramics Company)

"As one of our crucial problem was culture, we did not involve many current employees to make decision. We, at the top, did environmental scanning by our own. We observe directly, without bureaucratic barrier, how our people work in daily basis, then we decided what we should do for the future". (Farm Company)

Such top-down approach is in line with top leaders' role especially when companies faced turbulent situation. Beside their ability to initiate strategic moves, top leaders is the most responsible group in determine long term prosperity. Moreover, employees might trap to their functional or specific work silo, hence they could not comprehend overall situation and future trend.

\section{Attention to detail}

Leaders attention determined how employees attitude while working. As leader use attention to detail, follower might perceive they are under supervise. All leaders agreed that tight supervise were very useful while they recover company's performance. First, as top leader, they might have slightly insight about technical procedures. However, in 
order to cut their business process, leaders took more attention to such procedure and involved in determined of which should be subject to change or modified. As some leaders confessed:

"I gathered all of my accounting staff, and asked them to show and explain all accounting cost. We analyze each of those in order to achieve high level efficiency. I also asked our pharmacy department to report trend of medicine that prescript by doctor." (Private Hospital)

"Before produce our new line, top management asked to make simulation of factory layout. It was appeared that all of top management came to simulation room and pay attention on each alternative carefully." (Ceramics Company)

Beside to get sufficient information of technical procedures, leaders slumped into specific detail to send their employees a massage of how important such details in recovering process. This approach has helped leader ensuring their employees to take serious attention on what they did. Furthermore, attention to detail have made employees feeling under monitor and supervise.

\section{Open communication}

As the companies were in poor performance, many discomfort and anxiety feeling cover up employees' perception. Scared of being fire, ambiguity of companies' future, or at least resistant feeling on possible change plan surrounded work atmosphere. Furthermore, as leaders confessed that the first job they did in recovery program was communicating realistic situation and possible turn back that might occurred. More importantly was how leaders explained the role of employees in such process.

As leader said, there were many concern came up from employees about their future job in the company. Most leaders confessed that they received many kind of resistance from employees, especially those who laying off their personnel. In such condition, open communication is necessary, leaders have to create open discussion in order to quieten their employees.

Open communication was also necessary to establish commitment to change in entire organization. Top leaders were dependent on their employees to implement operational tactics especially those having required capabilities and experiences. Particularly, open discussion have helped leaders to change mind set and attitude of their employees toward transformational program. However, as some leaders argued that open communication should go on continuously. Leaders confessed that:

“...another important things to do when I did transformational operation is how to change engineering mind-set of my colleagues to services and marketing orientation. My colleague in parent company were mostly engineer. Their orientation were always quality and short time. However, turnaround process takes time, it (results) cannot be seen on a short time period". (Private Hospital)

"Ineed my employees to help me recover this company. First they have to understand the situation, then I guarantee that they will not be fired. Such assurance has helped me to keep their commitment". (Textile Company)

Company in substantially decreasing performance will implicate to the moral of their employees. However, leader have learned that their success in such turnaround are highly dependent on employees' commitment. Therefore, as leaders, they need to orchestrate several way to maintain employees moral and commitment. Despite of many other approaches, most leaders argued that open communication was the most imperative attitude in turnaround process.

\section{Conclusions}

Turnaround could occurs for some causes which were lack of vision and inability to anticipate competitive moves, poor corporate culture and operation, and inability to manage in slow economy condition. Leaders usually difficult to notice the initial beginning of turnaround situation, decreasing performance often look as normal phenomena, until formal audit or the performance fall significantly. Turn around process have its pattern. First, Leader realized substantial decreasing of company's performance. At this stage Leaders tend to carefully conducting environmental scanning of their company. Second, Leader will initiate turnaround strategy. However, after few attempts, decreasing performance was remain. Company is situation will not directly recover after initiating several action until certain personal. Next, decreasing performance will touch It peace fall, and It will rebound to a normal performance. This pattern indicated that turnaround process required continuous attempts on a particular time of period, and it usually takes time to indicate favorable turn back.

Most leader did not employed a robust and scientific approach of environmental scanning on decision making process. However, rational decisions were made using simple observation and analysis, mostly based on leader's judgment and perception. There are two focus of leaders in turn around financial strategy. First, an attempts to gain extra fund or capita in order to initiate the $r$ their new strategy. Since the companies are in risky position, it will be avert difficult for them to generate extra money from conventional funding institution. Therefore, Leader should come up with alternative idea of financing. Another focus was reducing operational cost through cost-benefit 
analysis. Main purpose in this stage is to achene high Level of efficiency.

Removal of few employees was a prominent option in turnaround strategy. Most leader used such approach in order to cut their expanses or replace with suitable new talent. Removal will lead to instable Removal will lead to instability of work atmosphere. There for, leaders need to maintain internal condition in productive good condition. Open Communication was believed as the most important approach on keeping employees morale and commitment. The most important action in turnaround process was redesign business process. Seeking for new sources of in pot and materials, change and modify the way of work, cut in value creation process were some of operational alternatives. Moreover, it seems a pattern that companies have to sacrifice their current valuable resources such as product line, process, or valuable asset to recover its operational.

Despite of contingency argument of how leaders should lead, it appeared that leaders came up with similar approach. They tend to use top down approach in making strategic decisions and general directions. Not only on strategic issues, top leaders were also highly involved in operational details, analyzing current business process, calculating costbenefit, and design new operational approaches. Open and close communication style was necessary in turnaround process. Many resistant will come from employees as well as decreasing work morale. Leaders' need to communicate rationally to man can productive work environment.

This study could enhance detail understanding on how leaders implementing turnaround strategy particularly in the context of Indonesia's companies. Important implication for top management in turnaround situation is how to early detect the symptoms preceding substantial decrease of performance. Early detection of turnaround should be considered as the further area of investigation related to turnaround strategy. Besides, leaders need to maintain situation under productive condition, and in the same time run companies on the right recovery track. There will be many resources affected by such process, and it will not get pay off directly. However, consistent implementation of the strategy will lead to recovery performance. This study have several limitation. Author might trapped on perception bias on extracting data, diverse industry might only generate general impression on turnaround process. Furthermore, number of informant might not sufficient to cover high level of generalization.

\section{References}

Abebe MA (2010) Top team composition and corporate turnaround under environmental stability and turbulence. Leadership \& Organization Development Journal 31 (3): 196-212. https://doi.org/10.1108/01437731011039325
Arogyaswamy K, Barker V, Yasai-Ardekani M (1995) Firm turnarounds: an integrative two-stage model. Journal of Management Studies 32 (4): 493-525. https://doi. org/10.1111/j.1467-6486.1995.tb00786.x

Barker V, Barr P (2002) Linking top manager attributions to strategic reorientation in declining firms attempting turnarounds. Journal of Business Research 55 (12): 963. https:// doi.org/10.1016/S0148-2963(00)00217-4

Barker V, Patterson P Jr (1996) Top management team tenure and top manager causal attributions at declining firms attempting turnarounds. Group \& Organization Management 21 (3): 304-336. https://doi.org/10.1177/1059601196213004

Barker V III, Duhaime I (1997) Strategic change in the turnaround process: theory and empirical evidence. Strategic Management Journal 18 (1): 13-38. https://doi.org/10.1002/ (SICI)1097-0266(199701)18:1<13::AID-SMJ843>3.0.CO;2-X

Barker V, Patterson J, Mueller G (2001) Organizational causes and strategic consequences of the extent of top management team replacement during turnaround attempts. Journal of Management Studies 38 (2): 235-269. https://doi.org/10.1111/14676486.00235

Barney J (2001) Is the resource-based view a useful perspective for strategic management research? Yes. Academy of Management Review 26: 41-56.

Boyd DP (2011) Lesson from turnaround leaders. Strategy \& Leadership 39 (3): 36-43. https://doi.org/10.1108/ 10878571111128801

Boyne G, Meier K (2009) Environmental change, human resources and organizational turnaround. Journal of Management Studies 46 (5): 835-863. https://doi.org/10.1111/j.1467-6486. 2008.00813.x

Brege S, Brandes O (1993) The successful double turnaround of ASEA and ABB - twenty lessons. Strategic Change 2 (4): 185-205. https://doi.org/10.1002/jsc.4240020403

Cameron K, Kim M, Whetton D (1987) Organizational effects of decline and turbulence. Administrative Science Quarterly 32 (2): 222-240. https://doi.org/10.2307/2393127

Creswell JW (2009) Research design: qualitative, quantitative, and. mixed methods approaches. Newbury Park: Sage Publications.

Day G, Moorman C (2013) Regaining customer relevance: the outside-in turnaround. Strategy and Leadership 41 (4): 17-23. https://doi.org/10.1108/SL-04-2013-0021

Evans RT, Chitnomrath T, Christopher T (2013) Successful turnaround strategy: Thailand evidance. Journal of Accounting in Emerging Economies 3 (2): 115-124. https://doi. org/10.1108/20421161311288848

Finkeilstein S, Hambrick DC, Cannella AA (2009) Strategic leadership: theory and research on executive, top management team, and boards. Oxford University Press.

Francis JD, Desai AB (2005) Situational and organizational determinants of turnaround. Management Decision 43 (9): 1203-1224. https://doi.org/10.1108/00251740510626272

Hambrick DC, Mason PA (1984) The organization as a reflection of its top managers. Academy of Management Review 9 (2): 193-206. https://doi.org/10.5465/amr.1984.4277628 
Hambrick DC (2007) Upper echelons theory: an update. Academy of Management Journal 32 (2): 334-343. https://doi. org/10.5465/amr.2007.24345254

Harker M (2001) Market manipulation: a necessary strategy in the company turnaround process? Qualitative Market Research: An International Journal 4 (4): 197-206. https://doi. org/10.1108/13522750110404771

Harker M, Sharma B (2000) Leadership and the company turnaround process. The leadership \& Organizational Development Journal 21 (1): 36-47. https://doi.org/10.1108/ 01437730010310721

Herri, Johan AP, Handika RF, Yulihasri (2017) CEOs characteristics and the successful of turnaround strategy: evidances from Indonesia. Academy of Strategic Management Journal 16 (1) https://www.abacademies.org/journals/month-aprilyear-2017-vol-16-issue-1-journal-asmj-past-issue.html

Lawson E, Price C (2003) The psychology of change management. The McKinsey Quarterly, 30-41.

Lawton T, Rajwani T, O'Kane C (2011) Strategic reorientation and business turnaround: the case of global legacy airlines. Journal of Strategy and Management 4 (3): 215-237. https:// doi.org/10.1108/17554251111152252

Lohrke F, Bedeian A, Palmer T (2004) The role of top management teams in formulating and implementing turnaround strategies: a review and research agenda. International Journal of Management Reviews 5/6 (2): 63-90. https://doi. org/10.1111/j.1460-8545.2004.00097.x

Merriam SB (2009) Qualitative research: a guide to design and implementation. San Francisco, CA: John Wiley \& Sons.

Morgan G (2006) Images of organization. California: Sage Publication.

Morrow JRJ, Johnson RA, Busenitz L (2004) The effects of cost and asset retrenchment on firm performance: the overlooked role of a firm's competitive environment. Journal of Management 30 (2): 189-208. https://doi.org/10.1016/j.jm.2003.01.002

Morrow JRJ, Sirmon DG, Hitt MA, Holcomb TR (2007) Creating value in the face of declining performance: firm strategies and organizational recovery. Strategic Management Journal 28 (3): 271-283. https://doi.org/10.1002/smj.579
Mueller G \& Barker V (1997) Upper echelons and board characteristics of turnaround and non-turnaround declining firms. Journal of Business Research 39 (2): 119-134. https:// doi.org/10.1016/S0148-2963(96)00147-6

Panicker S, Manimala MJ (2015) Successful turnarounds: the role of appropriate enterpreneurial strategies. Journal of Strategy and Management 8 (1): 21-40. https://doi.org/10.1108/JSMA06-2014-0050

Pearce J II, Robbins D (1993) Toward improved theory and research in business turnarounds. Journal of Management 19 (3): 613-636. https://doi.org/10.1177/014920639301900306

Porter M (1979) How competitive force shape strategy. Harvard Business Review, March.

Prahalad CK, Hamel G (1990) The core competence of the corporation. Harvard Business Review, May/June 79-91.

Pretorius M (2008) When Porter's generic strategies are not enough: complementary strategies for turnaround situations. Journal of Business Strategy 29 (6): 19-28. https://doi. org/10.1108/02756660810917200

Schoenberg R, Collier N, Bowman C (2013) Strategies for business turnaround and recovery: a review and synthesis. European Business Review 25 (3): 243-262. https://doi. org/10.1108/09555341311314799

Sekaran U (2003) Research methods for business: a skill building approach (4th ed) USA. Hermitage Publishing Services.

Smith M, Graves C (2005) Corporate turnaround and financial distress. Managerial Auditing Journal 20 (3): 304-320. https:// doi.org/10.1108/02686900510585627

Stake RE (2010) Qualitative research: studying how things work. New York, NY: Guilford Press.

Van Wittelstuijn A (1998) Bridging behavioral and economic theories of decline: organizational inertia, strategic competition, and chronic failure. Management Science 44 (4): 501-519. https://doi.org/10.1287/mnsc.44.4.501

Zimmerman F (1989) Managing a successful turnaround. Long Range Planning 22 (3): 105-124. https://doi.org/10.1016/00246301(89)90013-7 